\title{
Early child development: nature or nurture?
}

\author{
Kalyani Guruge ${ }^{1}$ \\ Sri Lanka Journal of Child Health, 2010; 39:4-10
}

(Key words: Early childhood development)

Today we are witnessing what could reliably be called either a "baton change in a relay" or the "changing of the guard" in a palace. Both are exciting and interesting events to watch and it becomes a proud moment for the key player. I feel greatly honoured and privileged to be that key player today.

A President of this august College is inducted ceremonially to commence his or her year of presidency. At the end of the tenure of the president there is a Scientific Congress where academic deliberations take place and the Congress ends up with the banquet. In between the glitter of the induction and the glamour of the Scientific Congress, there is a great deal of hard work that has to be undertaken in that entire year.

Dr. H. T. Wickramasinghe, you may remember, that you handed over the baton to me, once before, in October 1975 when I started internship, in the same ward in which you had just completed your internship. You did hold a good track record then and this time too, when you are doing the same in handing over the Presidency of the Sri Lanka College of Paediatricians, you have once again proved that you are a capable captain.

I am intensely aware of the responsibilities that this particular position entails and I stand here, in all humility, to carry forward the good work undertaken by the many giants in paediatrics who have gone through this mill before me. I appreciate the confidence placed in me indicating that I do indeed deserve this great honour. It is my fervent hope that every single one of you present today will wholeheartedly support and help me to carry out the responsibilities of this exalted position.

When my name was proposed more than a year ago, I started making plans for this year. The theme swiftly moved from nutrition to environment and from home accidents to rational drug policy. I wish and pray that we will be able to tackle all these

${ }_{\text {Consultant Paediatrician, Lady Ridgeway }}$
Hospital, Colombo

*Address given on induction as President SLCP, November 2009 complex problems during the course of this year. Yet for all that, the year seems to be too short for the onerous tasks ahead. In view of this, we have already started the ball rolling by beginning the initial efforts towards working on public education on home accident prevention.

In my 34 years of professional life, most of it spent working with children, there were so many instances when I have had to listen to mothers who complained and blamed their children for many a thing. I am sure these stories are familiar to most of you. The saga usually starts with plaintive cries like "My baby does not like breast milk", "He turns the head away when I try to feed", "We cannot feed our daughter", "She screams when food is brought anywhere near her", "She turns the plate upside down when food is brought to her", "The boy is very naughty, he hits and bites me", "He gets very angry and throws the toys around". Subsequently, this has then gone through the phase of "My son watched TV the whole evening and started doing his homework only at ten in the night" and then on to "Doctor, please tell my adolescent daughter to eat vegetables as they are so good for the eyes. She will not listen to me and eats only potatoes and sausages". I ask you, ladies and gentlemen, aren't all these parenting issues?

Guiding the parent was the starting point for the theme for this year. However, later it was expanded to early childhood development as well. The world of children and the work of the paediatrician are inextricably interwoven. The world should really be a beautiful place to be born into but the challenges the child has to face are enormous. The disparities start right from conception. From then onwards and beginning from innocent childhood, the opportunities to grow into responsible adult life depends on which region of the world a child is born into and the social class the child belongs to.

The challenge to enable all children to develop to their full potential is a gigantic one. Children from different socio-economic groups differ widely in their achievements in later life. There is good evidence that effective interventions initiated in the early years of life make a significant difference. This phenomenon appears to be of the greatest value for the most disadvantaged children. In fact, 
the latter group is the one that needs it most. Thus, my abiding interest in early childhood development!

It is estimated that more than 200 million children under 5 years fail to reach their full potential in cognitive, language and socioeconomic development ${ }^{1}$. Many of these children, nearly 89 million, live in South Asia and South East Asia ${ }^{1}$.

Out of the different developmental domains only cognitive development is comparable across countries as data is not available for others. The children brought up in a more nurturing and stimulating environment achieve higher cognitive levels. The discrepancy between the current development and what the child would have achieved in a more nurturing and stimulating environment indicates the degree of loss of potential.

In later childhood these children will do poorly in school resulting in less earning capacity; they have high fertility and malnutrition and in turn their children will also have poorer health care, nutrition and non stimulating home environment leading to intergenerational transmission of poverty.

The stunted and poor children's inability to reach their full potential results in a $20 \%$ deficit in yearly adult income costing billions for each nation's productivity ${ }^{1}$. The loss in adult income from being stunted is $22 \%$ and loss of living is poverty is $5 \%$, loss of being poor and stunted is nearly $30 \%{ }^{1}$.

The first United Nations millennium development goal $^{2}$ is to eradicate extreme poverty and hunger, and the second is to ensure that all children complete primary schooling ${ }^{2}$.

Disadvantaged children have fewer years of schooling and less learning per year in school. The deficit in learning from being poor and stunted when compared with non stunted is equivalent to 2.15 grades $^{1}$. With improvements of education of the parents, especially of the mother, the child survival, health, nutrition, cognition and education improve. The changes in earning capacity of individuals ultimately affect the national economic development. Studies from 51 countries show that on average each year of schooling increases the wages by $9.7 \%{ }^{3}$.

The first few years of life are very important as vital development occurs in all domains. The brain development is rapid with neurogenesis, synaptogenesis and myelination taking place in the early years of life. Brain development is genetically influenced but modified by the environment. Exposure to biological and psychological risks affects the function and structure of the brain. The damages suffered early in life might also affect future generations. Despite the vulnerability of the brain to early insults remarkable recovery is often possible with interventions; earlier the interventions greater is the benefit.

Biological risk factors that affect child development include intrauterine growth restriction, child undernutrition, iron, iodine, zinc and vitamin A deficiencies, poor breast feeding, infectious diseases and environmental toxins. Intra uterine growth restriction in Brazilian children was shown to have lower cognitive scores at 12 months than infants born with birth weight above 3000 grams ${ }^{4}$. In studies done in both Brazil and Jamaica low birth weight babies were rated as less active, vocal, happy or cooperative $e^{4,5}$. The critical role of nutrition for the development of cognitive skills had been shown in many studies ${ }^{6-10}$. The most consistently related to poor cognitive development are stunting, iron and iodine deficiency ${ }^{11}$. Other nutrients probably play a critical role but are only now beginning to be recognized. Nutrition also has an impact on emotionality, irritability, attention and social responses. The central nervous system damaged and irritable small passive children treated as they were younger than what they really are also has an impact on their cognitive deficit, school achievement and later school dropouts. A 2005 meta-analysis of 37 studies of 12,291 Chinese children concluded that IQ average 12.5 points lower for children growing up in iodine deficient $\operatorname{areas}^{12}$. Nineteen of 21 studies reported poorer mental, motor and socio-emotional functioning in infants with iron deficiency anaemia ${ }^{13,14}$.

Research from developed countries has identified 3 psychosocial risk factors of parenting that are consistently related to development. They are: cognitive stimulation, caregiver's sensitivity and responsiveness to the child and caregiver's emotional warmth or rejection of the child ${ }^{15}$.

Important risk factors that affect brain development are inadequate cognitive stimulation, stunting, iron deficiency and iodine deficiency ${ }^{11}$. Randomized intervention studies in South Africa, Jamaica and Turkey show significantly higher functions in young children given additional learning opportunities than non stimulated controls ${ }^{16-18}$. Follow up studies report lasting effects of early cognitive stimulation, with some gains lasting up to 17 years ${ }^{16,18,19}$. This strongly supports the importance of early cognitive stimulation.

The most critical elements of care for child wellbeing are maternal sensitivity (being able to read the child's signals) and responsivity (responding appropriately to the child's signals) ${ }^{15}$. 
Studies from Chile, Columbia and South Africa show maternal sensitivity was associated with more secure infant attachment, cognitive ability and reduced levels of behaviour problems in preschool children $^{20-22}$. Maternal sensitivity is the most crucial for child development. Maternal depression affects maternal child rearing behaviour. In South Africa depressed mothers were less involved and less sensitive when interacting with their children ${ }^{23}$.

United Nations Convention on the Rights of the Child ensures that every child has the best start to life to survive and develop, have the right to highest attainable standard of health, the right to develop to their full potential, parented by both mother and father ${ }^{24}$. Based on the UN convention for rights of the child are a set of actions for ensuring early childhood development (ECD). These include rights to grow up healthy, well nourished, protected from harm and abuse, with a sense of identity, self-worth and dignity, independence and opportunities for learning. ECD may be a new term but the concept has always been with us; have a look at how the birds and mammals practice ECD. Early childhood development is an umbrella term for a variety of interventions centred on young children, their caregivers and families including health, nutrition, child care, education and parenting and parent support during the formative years.

To achieve ECD interventions are centred on young children, their caregivers and families. They include childcare, education and parent support during the early years. The enriched environment and the quality of stimulation, security and support during the sensitive periods of development are of the utmost importance from conception to 8 years. The amount of language a child hears, particularly language used in a meaningful way such as conversation with child rather than on television, is strongly associated with language development which in turn helps school performance and success. Learning materials that provide opportunities for touching, manipulation and problem solving is an important support for learning. Books and pictures introduce a child to written words and build on vocabulary as do playing with adults or older siblings. When ECD is linked to programmes to support nutrition, the effects become additive and synergistic. Nineteen combined ECD programmes and nutrition interventions models have been assessed ${ }^{25}$. Evidence shows that this is the most cost effective intervention during the child's most vulnerable years.

Early child development interventions in the first 3 to 4 years have resulted in improved child outcome resulting in the long term benefits of 3 to 17 dollars for every dollar spent both in the United States of America and developing countries ${ }^{26}$.

Sri Lanka has moved away from a focus on child survival to a broader concern for child development. Sri Lanka records low figures for child mortality and recognizes the children's right to survive and develop. The country has moved from the focus on survival to development but child undernutrition and poverty are still problems for Sri Lanka. National poverty line is at $15.2 \%$ with estate population still recording $32 \%{ }^{27}$. Twenty two percent of children below 5 years are underweight and $18 \%$ are short for their age a $^{28}$. Seventeen percent of newborns are of low birth weights $^{28}$. Although our health indicators are excellent we are still lagging behind in nutrition indicators.

Let us consider the history of child development in Sri Lanka. Development screening and home risk factors were incorporated into the child health development record (CHDR) since early 1980s. A project to promote child development was started in the early 1990s and a project to optimise children with delays in the late1990s and they were revamped in 2002 under early childhood care and development (ECCD). A national policy on ECCD was formulated in 2004 by the Ministry of Child Development \& Women's Empowerment ${ }^{29}$.

As mentioned initially, 89 million children in South and Southeast Asia are unable to reach their developmental potential due to poverty, poor education of the parents and non-stimulating home environment ${ }^{1}$. We decided to ascertain whether this situation is applicable to Sri Lanka by carrying out a field study on parenting in preschool children. The study sample was drawn from four districts viz. Colombo, Kandy, Nuwara Eliya and Monaragala which represent different ethnic groups and rural and urban populations. From each district one medical officer of health $(\mathrm{MOH})$ area was selected and from each $\mathrm{MOH}$ area 78 random samples were obtained from a group of midwives, nurses, preschool teachers and parents.

Each family was assessed for their socio-economic status based on 10 variables. They were grouped into four classes. Class 1 had the lowest household score and Class 4 the highest. Classes 1 and 2 comprised $32 \%$ of the sample. Education of the mothers was up to grade 13 or more in $68 \%$ whilst in $7 \%$ mothers, education was below grade 8 . The mother's educational level and class position correlated positively, the better the education of the mother, the higher the class position. Mother was the primary caretaker in $84 \%$ of families, the other caretakers being father $(13 \%)$, adult relatives $(1.5 \%)$, grandparents $(1 \%)$ and others $(0.5 \%)$. In 
poor families (class 1) mother was working or absent most of the time so that other people had to act as the primary caretaker. This difference was statistically significant $(\mathrm{p}<0.05)$. Primary caretakers of higher classes were more educated than those of lower classes. This was statistically significant $(\mathrm{p}<0.05)$.

In doing the study 20 questions were administered. However, for the purpose of the presentation only 10 were considered as my time was limited. The questions were based on:

1. Parenting practices in the first 6 months (Figure 1)

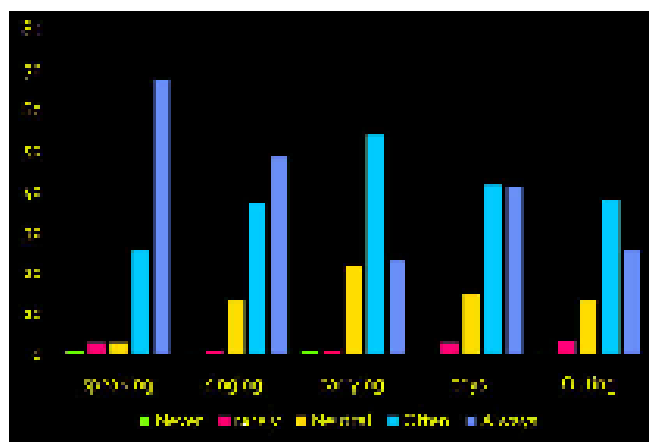

Figure 1: Parenting practices in the first six months

2. Caring for a crying child (Figure 2).

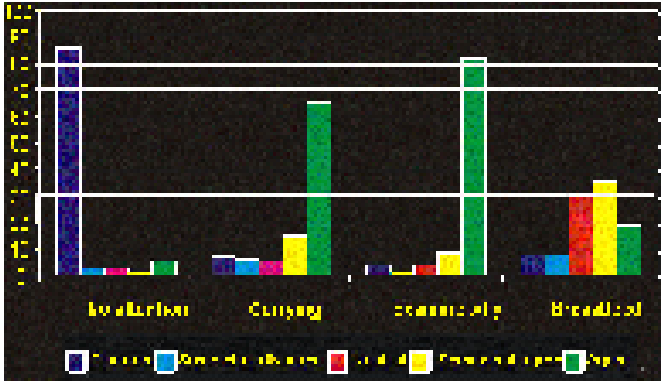

Figure 2: Caring for a crying child

3. Parenting a 2 year old child (Figure 3 ).

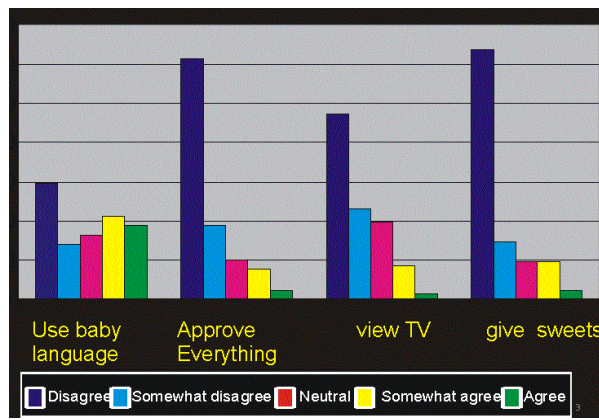

Figure 3: Parenting a 2 year old child
4. Attitude to child's exploration. (Figure 4).

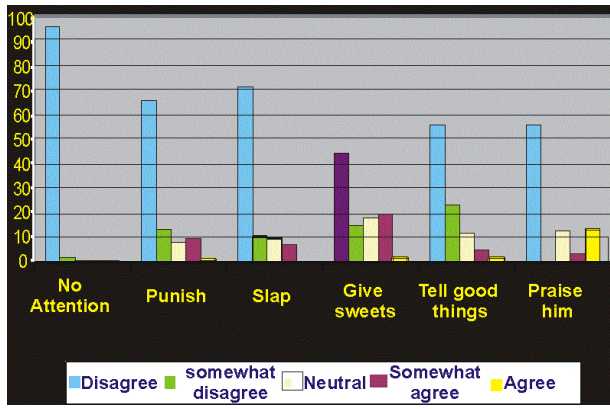

Figure 4: Attitude to child's exploration

5. Handling of child by working parents after retuning from work (Figure 5).

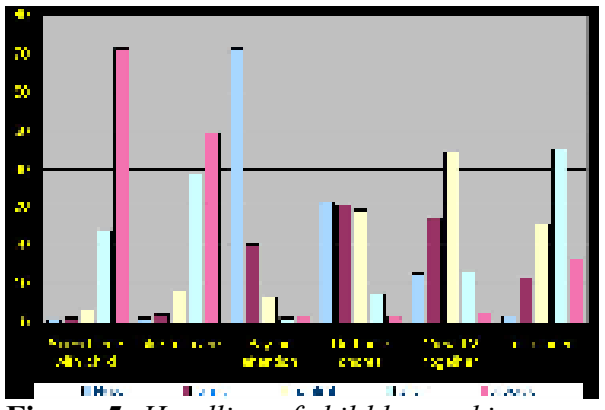

Figure 5: Handling of child by working parents after returning from work

6. Quality of time spent with the child (Figure 6).

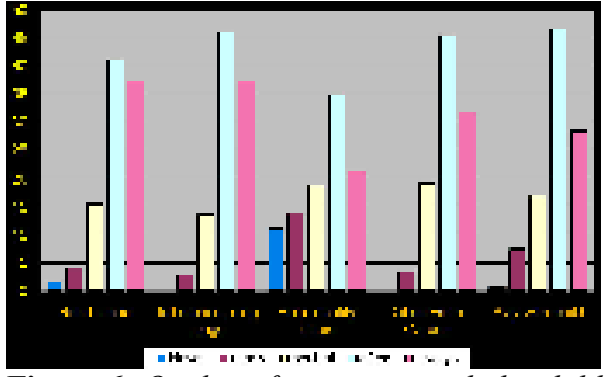

Figure 6: Quality of time spent with the child

7. Child creative activities like drawing on walls (Figure 7).

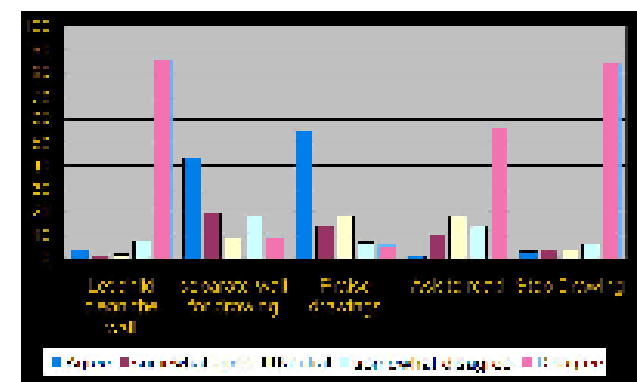

Figure 7: Child creative activities like drawing on walls 
8. Selection of toys for children (Figure 8).

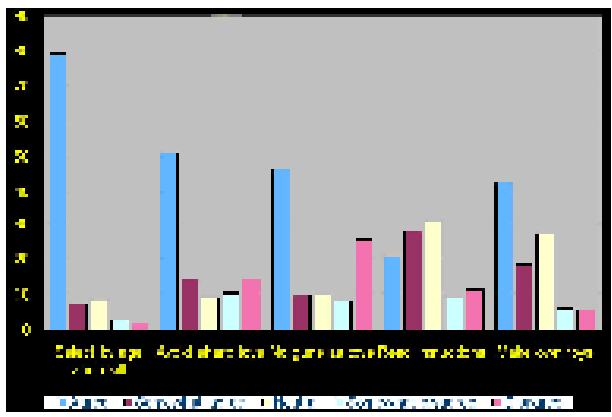

Figure 8: Selection of toys for children

9. Response to play, studying and TV time (Figure 9).

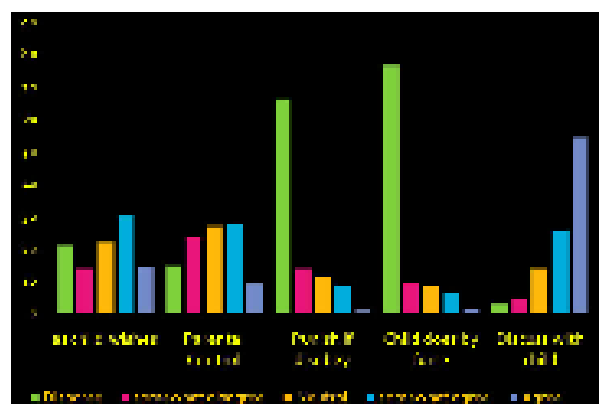

Figure 9: Response to play, studying and TV time

10. Spending time with the family (Figure 10).

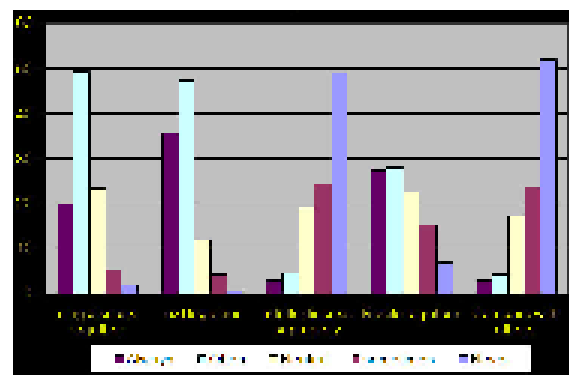

Figure 10: Spending time with the family

\section{Correlations}

1. There was correlation between family social status (class) and caring practices during the first 6 months of life.

2. There was a significant association between family social status (class) and caring for a crying child $(\mathrm{p}<0.05)$.

3. There was a significant correlation between family social status (class) and care of a 2 year old child $(\mathrm{p}<0.005)$.

4. There was no significant correlation between working mother's education and child care practices $(\mathrm{p}>0.05)$.

5. There was a significant correlation between social status and family gathering $(\mathrm{p}<0.001)$.
6. There was a significant correlation between maternal education \& family gathering $(\mathrm{p}<0.001)$.

We prepared an ECD index based on the responses to the $10 \mathrm{ECD}$ questions to summarize them for clarity and brevity.

- The ECD index on parental care during early childhood by all classes of families was highly significant $(\mathrm{p}<0.005)$.

- The ECD index by education of all mothers was highly significant $(\mathrm{p}<0.001)$.

- The ECD index by education of poor mothers was also significant $(\mathrm{p}<0.05)$.

- Good ECD practices are significantly more in higher income groups and better educated families.

\section{Conclusions}

- Education of the mother is important in parenting during formative years.

- Poor and lower middle class families comprise about $30 \%$ of the population sample. Class plays a formidable role in parenting. Families of the poor and lower middle classes display poor parenting practices. The attachment bonds between parent and child is evident to be absent in lower social classes.

- Ability to invest time in parenting by mother is considerably low in the poorer classes. In place of mother, many others play the role of care taker. Lack of good parenting practices were more pronounced in the poor families when the mother is absent.

- Poor parenting in lower classes of households was found in all four districts.

- Health workers displayed better attitudes to ECD and parenting.

- Majority of families in the community displayed a poor attitude and knowledge towards ECD.

- A large percentage of preschool teachers had the same poor practices of ECD as the community.

- This group needs targeted and focused parenting programmes to improve the early childhood development effort.

Studies show that children who receive assistance in their early years achieve more success at school and have higher employment and earning and better health.

We cannot afford to lose the potential of our future adults. Every child has a right to survive and develop. Paediatricians have worked hard for the survival of the child. May I ask you ladies \& 
gentleman to please let us help guide the families to provide stimulating care for there children as well as give good nutrition.

\section{References}

1. Grantham-McGregor S, Cheung YB, Cueto S, for the International Child Development Steering Group. Developmental potential in the first 5 years for children in developing countries. Lancet 2007; 369: 60-70.

2. Millenium development goals. Available from: http://www.undp.org/mdg/basics.shtml

3. Psacharapoulos G, Patrinos H. Returns to investment in education: a further update. Educ Econ 2004; 12: 111-34.

4. Grantham-McGregor SM, Lira PI, Ashworth A, Morris SS, Assuncao AM. The development of low birth weight infants and the effects of the environment in northeast Brazil. J Pediatr 1998; 132: 661-6.

5. Gardner JM, Walker SP, Powell CA, Grantham-McGregor SM. A randomized controlled trial of a home-visiting intervention on cognition and behaviour in term low birth weight infants. $J$ Pediatr 2003; 143: 634-9.

6. Weber DP, Vuori-Christiansen L, Ortiz N, et al. Nutritional supplementation, maternal education and cognitive development of infants at risk of malnutrition. Am J Clin Nutr 1981; 34: 807-33.

7. Grantham-McGregor SM, Powell CA, Walker SP, Himes JH. Nutritional supplementation, psychosocial stimulation, and mental development of stunted children: the Jamaican study. Lancet 1991; 338: 1-5.

8. Husaini MA, Karyadi L, Husaini YK, Sandjaja, Karyadi D, Pollitt E. Developmental effects of short-term supplementary feeding in nutritionally-at-risk Indonesian infants. $\mathrm{Am} \mathrm{J}$ Clin Nutr 1991; 54: 799-804.

9. Pollitt E, Gorman KS, Engle PL, Martorell R, Rivera J. Early supplementary feeding and cognition: effects over two decades. Monogr Soc Res Child Dev 1993; 58: 1-99.

10. Pollitt E, Schurch B. Developmental pathways of the malnourished child. Results of a supplementation trial in Indonesia. Eur J Clin Nutr 2000; 54 (suppl 2): 2-113.
11. Walker S, Wachs T, Meeks Gardner J, Lozoff B, Wasserman G, Pollitt E, Carter J. Child development: risk factors for adverse outcomes in developing countries. The Lancet 2007; 369 (9556): 145-57.

12. Qian M, Wang D, Watkins WE. The effects of iodine on intelligence in children: a metaanalysis of studies conducted in China. Asia Pac J Clin Nutr 2005; 14: 32-42.

13. Lozoff B, Beard J, Connor J, Felt B, Georgieff $\mathrm{M}$, Schallert T. Long-lasting neural and behavioural effects of iron deficiency in infancy. Nutr Rev 2006; 64: S34-S43.

14. Grantham-McGregor S, Ani C. A review of studies on the effect of iron deficiency on cognitive development in children. $J$ Nutr 2001; 131: 6495-665.

15. National Research Council and Institute of Medicine. From neurons to neighbourhoods. The science of early childhood development. Washington DC: National Academy Press, 2000 .

16. Magwaza`A, Edwards S. An evaluation of an integrated parent-effectiveness training and children's enrichment programme for disadvantaged families. S Afr J Psychol 1991; 21: $21-25$.

17. Meeks Gardner J, Walker SP, Powell CA, Grantham-McGregor S. A randomized controlled trial of a home-visiting intervention on cognition and behaviour in term low birth weight infants. J Pediatr 2003; 143:634-9.

18. Kagitcibasi C, Sunar D, Bekman S. Long-term effects of early intervention: Turkish lowincome mothers and children. J Appl Dev Psychology 2001; 22: 333-61.

19. Walker SP, Chang SM, Powell CA, GranthamMcGregor SM. Effects of early psychosocial stimulation and nutritional supplementation on cognition and education in growth-stunted Jamaican children: prospective cohort study. Lancet 2005; 366: 1804-7.

20. Posada G, Jacobs A, Carbonell OA, Alzate G, Bustamante MR, Arenas A. Maternal care and attachment security in ordinary and emergency contexts. Dev Psychol 1999; 35: 1379-88.

21. Tomlinson M, Cooper P, Murray L. The mother-infant relationship and infant attachment in a South African peri-urban settlement. Child Dev 2005; 76: 1044-54. 
22. Valenzuela M. Maternal sensitivity in a developing society: the context of urban poverty and infant chronic undernutrition. Dev Psychol 1997; 33: 845-55.

23. Cooper PJ, Tomlinson M, Swartz L, Woolgar M, Murray L, Molteno C. Postpartum depression and the mother-infant relationship in a South African peri-urban settlement. $\mathrm{Br} J$ Psychiat 1999; 175: 554-8.

24. Convention on the rights of the child. From Wikipedia, the free encyclopedia. Available from:

http://en.wikipedia.org/wiki/Convention on th e Rights of the Child

25. Watanabe K, Flores R, Fujiwara J and Lien Tran LTH. Early childhood development interventions and cognitive development of young children in rural Vietnam. $J$ Nutr 2005; 135:1918-25.

26. Lynch RG. Economic, fiscal, and social benefits of investment in early childhood development. Washington DC: Economic
Policy Institute 2004. Available from: http://www.montanakidscount.org/Portals/6/re ports/exceptional $\% 20$ returns.pdf

27. Department of Census and Statistics, Ministry of Finance and Planning, Sri Lanka March 2008. Poverty Indicators: Household Income and Expenditure Survey - 2006/07. Available from:

http://www.statistics.gov.lk/poverty/PovertyIn dicators.pdf

28. Department of Census and Statistics in collaboration with Ministry of Health care and Nutrition May 2008. Sri Lanka Demographic and Health Survey 2006/2007. Available from: http://www.statistics.gov.lk/DHS/DHS\%20Sri \%20Lanka \%20Preliminary\%20Report.pdf

29. Expanding early childhood care and education. Available from: ww.unescobkk.org/.../user.../SriLankaEFA MDA08 Ch2 1.pdf 